\title{
Assessment of anxiety and health-related quality of life in patients with lower extremity peripheral arterial occlusive disease
}

\author{
Yalcin Guzelhan ${ }^{1}$, Didem Melis Oztas², Cenk Conkbayir ${ }^{3}$, Orhan Rodoplu ${ }^{4}$, Ibrahim Erdinc ${ }^{5}$, \\ Cagla Canbay ${ }^{6}$, Murat Ugurlucan ${ }^{6}$, Ufuk Alpagut ${ }^{6}$, Nilgun Bozbuga ${ }^{6}$
}

\begin{abstract}
'Department of Psychiatry, Istanbul Education and Research Hospital, Istanbul, Turkey ${ }^{2}$ Cardiovascular Surgery Clinic, Bagcilar Training and Research Hospital, Istanbul, Turkey ${ }^{3}$ Department of Cardiology, Near East University, Nicosia, Cyprus ${ }^{4}$ Cardiovascular Surgery Clinic, Kadikoy Medicana Hospital, Istanbul, Turkey ${ }^{5}$ Cardiovascular Surgery Clinic, Izmir Bozyaka Education and Research Hospital, Izmir, Turkey

${ }^{6}$ Department of Cardiovascular Surgery, Istanbul Medical Faculty, Istanbul University, Istanbul, Turkey
\end{abstract}

Submitted: 17 May 2020

Accepted: 18 May 2020

Arch Med Sci Atheroscler Dis 2020; 5: e212-e218

DOI: https://doi.org/10.5114/amsad.2020.97728

Copyright $\odot 2020$ Termedia \& Banach

\section{Abstract}

Introduction: The aim of this study was to investigate the effect of chronic occlusive vascular disease on anxiety with adverse outcome with health-related quality of life (HRQoL).

Material and methods: Three hundred and thirty-five patients who were treated for peripheral arterial occlusive disease were enrolled in this study. 187 patients who had undergone percutaneous transluminal angioplasty and 148 patients who had one or more surgical revascularizations enrolled in the study. Mean age of the patients was $62.6 \pm 10$ years. Two hundred and eighty-nine patients were male, 46 patients were female. Physical and mental domains of quality of life were measured using the 36-item Medical Outcomes Short-Form Health Survey (SF-36) self-administered questionnaire and anxiety symptoms were assessed using the Spielberger State-Trait Anxiety Inventory (STAI). At baseline 335 patients filled out the SF-36 and STAI, and 304 patients ( $90.7 \%$ of the series) filled them out at 6-month follow-up. Results: There was no mortality and no significant morbidity after vascular interventions in the series. Significant improvement was found in two of eight health domains. The score of social functioning increased to 60.4 from $52.6(p<0.03)$ and general health perception increased to 75.1 from 60.5 $(p<0.04)$ at 6 -month follow-up. The two STAI sub-scores, the State Anxiety Inventory (STAI-S) and the Trait Anxiety Inventory (STAI-T) were found high $(\geq 40)$ both preoperatively and 6 months postoperatively. Postoperatively there was no significant decrease of the levels of anxiety.

Conclusions: This study suggests that the assessment of psychosocial factors, particularly the ongoing assessment of anxiety, could help in risk stratification and prediction of functional status in patients suffering from lower extremity peripheral arterial occlusive disease.

Key words: health-related quality of life, risk factors, peripheral arterial disease.

\author{
Corresponding author \\ Yalcin Guzelhan \\ Department of Psychiatry \\ Istanbul Education and \\ Research Hospital \\ Kasap ilyas Mah, Org. \\ Abdurrahman Nafiz Gürman \\ Cd. \\ 34098 Fatih/istanbul, Turkey \\ Phone: +90 5323854748 \\ E-mail: drguzelhan@gmail.com
}




\section{Introduction}

Peripheral arterial disease (PAD) is one of the important causes of morbidity and mortality. Atherosclerosis is the main etiological factor of peripheral artery disease [1]. The traditional objectives of intervention in patients with PAD have been symptomatic relief and limb salvage. In recent years, the goal of surgical intervention in patients with PAD has evolved to improve functional status. Patients are selected for intervention or surgery according to life-style limitation severity, ulceration or risk of limb loss. Although limb salvage and improving functional status are the stated goals of intervention or surgery in PAD by providing distal perfusion, the importance of these therapeutic goals lies in their potential for improving health-related quality of life (HRQoL) [2-4].

Physical factors, patient's health-related quality of life (HRQoL), such as physical health, psychological condition, and social relations, also influence the postoperative outcome and thereby long term survival after intervention or surgery [5]. Direct measurements of $H R Q O L$ in patients with PAD have been relatively uncommon.

The World Health Organization (WHO) describes quality of life as "an individual's perception of their position in life in the context of the culture and value system in which they live and in relation to their goals, expectations, and standards and concerns" [6]. Health-related quality of life includes individual's usual or expected physical, emotional and social states that are affected by the medical situation. According to the WHO's disease-specific quality of life group, any generic health-related quality of life instrument should contain physical, psychologic, social, functional, and well-being fields [7-10]. In peripheral arterial occlusive disease pathology, disease-specific quality of life measures aim to show a patient's condition of a specific illness or treatment [11, 12].

The aim of the present study was to investigate the influence of psychological factors on major adverse cardiac event and to evaluate the hypotheses that symptoms of anxiety are associated with adverse clinical outcomes and quality of life in patients with chronic occlusive vascular disease requiring vascular intervention or surgery.

\section{Material and methods}

Three hundred and thirty-five patients who were intervened for peripheral arterial occlusive disease were enrolled in this study. The study was performed according to the principles of the Declaration of Helsinki. Demographic data on age, gender and education level (number of school years) were recorded. At enrollment, participants reported their smoking history (grouped as never, former, < 20 cigarettes per day, and $\geq 20$ per day) (Table I).

Patient-related factors and comorbidities (diabetes mellitus, hypertension, hypercholesterolemia, obesity, ischemic heart disease, cerebrovascular disease, chronic renal failure, chronic obstructive pulmonary disease), clinical symptoms (claudication, atypical leg pain, ischemic leg pain, ulceration), angiographic findings (aorto-iliac disease, femoro-popliteal disease, distal artery disease) were recorded (Table II). Almost half of the series, 164 patients, have undergone previous lower extremity vascular surgery and 19 of them required contralateral amputation previously.

One hundred and eighty-seven patients who had undergone percutaneous transluminal angioplasty and 148 patients who had one or more surgical revascularizations enrolled in the study.

At baseline 335 patients filled out the 36 -item Medical Outcomes Short-Form Health Survey (SF-36) self-administered questionnaire [13] and the Spielberger State-Trait Anxiety Inventory

Table I. Patients' characteristics

\begin{tabular}{|c|c|c|}
\hline Parameter & $N$ & Percentage \\
\hline \multicolumn{3}{|l|}{ Sex: } \\
\hline Male & 289 & 86.3 \\
\hline Female & 46 & 13.7 \\
\hline \multicolumn{3}{|l|}{ Age: } \\
\hline Mean [years] & $62.6 \pm 10$ & \\
\hline $40-50$ & 16 & \\
\hline $51-60$ & 25 & \\
\hline $61-70$ & 34 & \\
\hline $71-80$ & 21 & \\
\hline$\geq 81$ & 1.5 & \\
\hline \multicolumn{3}{|l|}{ Education level: } \\
\hline Mean [years] & 6.95 & \\
\hline $\begin{array}{l}\text { Secondary school } \\
\text { and lower }\end{array}$ & 79.1 & \\
\hline High school & 12.4 & \\
\hline University and higher & 3.5 & \\
\hline \multicolumn{3}{|l|}{$\begin{array}{l}\text { Smoking history } \\
\text { (cigarettes per day): }\end{array}$} \\
\hline Never & 8 & 2 \\
\hline Former smoking history & 61 & 18.1 \\
\hline Current smoking history: & 266 & 79.4 \\
\hline$<20$ & 90 & 34 \\
\hline$\geq 20$ & 176 & 66 \\
\hline
\end{tabular}


(STAI) [14], 304 patients (90.7\% of the series) at 6-month follow-up. A range of psychosocial, clinical and operative factors were collected as potential determinants of outcome.

\section{Definition of Health-Related Quality of Life}

The 36-item Medical Outcomes Short-Form Health Survey (SF-36) includes 36 questions in eight domains: general health condition (past and present health), physical capacity (based on performance of daily living), pain (including intensity, frequency, duration and limitations in normal activities because of pain), mental status (emotional, cognitive, and intellectual conditions), physical life (usual activities according to age and social status), emotional life (feelings at work or daily activities), vitality (energy, fatigue, and tiredness), and social relationships. A score from zero

Table II. Risk factors, clinical and angiographic features

\begin{tabular}{|c|c|c|}
\hline Parameter & $N$ & Percentage \\
\hline \multicolumn{3}{|l|}{ Comorbidities: } \\
\hline Diabetes mellitus & 117 & 36.1 \\
\hline Hypertension & 234 & 78.8 \\
\hline Hypercholesterolemia & 272 & 83.3 \\
\hline Obesity & 83 & 24.7 \\
\hline Ischemic heart disease & 170 & 50.9 \\
\hline Cerebrovascular accident & 83 & 24.8 \\
\hline End-stage renal disease & 14 & 4.2 \\
\hline $\begin{array}{l}\text { Chronic obstructive } \\
\text { pulmonary disease }\end{array}$ & 140 & 41.8 \\
\hline $\begin{array}{l}\text { Previous lower extremity } \\
\text { vascular surgery }\end{array}$ & 164 & 49.1 \\
\hline $\begin{array}{l}\text { Previous contralateral } \\
\text { vascular surgery } \\
\text { amputation }\end{array}$ & 19 & 5.7 \\
\hline \multicolumn{3}{|l|}{ Symptoms: } \\
\hline Claudication & 117 & 35 \\
\hline Atypical leg pain & 165 & 49 \\
\hline Ischemic leg pain & 53 & 16 \\
\hline Ulceration & 80 & 24 \\
\hline \multicolumn{3}{|l|}{ Angiographic findings: } \\
\hline Aorto-iliac disease & 71 & 20 \\
\hline CFA occlusion & 161 & 48 \\
\hline PopA occlusion & 54 & 16 \\
\hline ATA-PTA disease & 54 & 16 \\
\hline
\end{tabular}

CFA - common femoral artery, PopA - popliteal artery, ATA - anterior tibial artery, PTA - posterior tibial artery. to 100 is computed for the 8 scales. The SF-36 can provide 2 summary measures as the physical element score and mental component score [15]. It has been beneficial in evaluating well-known and unique populations, comparing the relative burden of diseases, differentiating the health advantages produced by means of an extensive variety of different treatments, and screening individual patients [15].

\section{Measurement of anxiety}

The two Spielberger State-Trait Anxiety Inventory sub-scores, the state (STAI-S) and the trait (STAI-T), have a high relation in people with or without generalized anxiety disorder. It contains "I feel nervous" and "I feel worried" statements. These items are scored on a 4-point scale of how they define the patient's current or typical status from "not at all" to "very much so." STAI scores range from 20 to 80. Higher scores reveal more severe symptoms, greater anxiety. The two STAI sub-scores have high association in people with or without anxiety. We accepted STAI scores less than 40 to indicate that there are minimal symptoms or there are no symptoms and higher than 40 to indicate that there are moderate or severe symptoms [16].

\section{Statistical analysis}

Statistical analysis was performed using the statistical software SPSS 20.0 for Windows (SPSS Inc., Chicago, IL). Data are expressed as mean values \pm standard deviation for continuous variables and as numbers with percentage for categorical variables. The discrete variables were compared using the $\chi^{2}$ test and continuous variables were compared using a two-tailed $t$ test. Differences obtained from the pre- and postoperative assessments were compared by Wilcoxon matched-pairs rank-sum test. Univariate analysis and logistic regression analysis were performed to identify the potential risk factors associated with quality of life and anxiety. A p-value of 0.05 or less was considered to be significant.

\section{Results}

There was no mortality and no significant morbidity after vascular interventions in the series. All of the 335 patients completed a short-form health survey (SF-36) and psychological self-reported questionnaires (STAI-S and STAI-T tests) and 304 of the series $(90.7 \%)$ did so after a 6-month follow-up.

Significant improvement was found in two out of eight health domains - social functioning ( $p<$ $0.03)$ and general health perception $(p<0.04)-$ at 6-month follow-up. The two STAI sub-scores, the State Anxiety Inventory (STAI-S) and the Trait 
Anxiety Inventory (STAI-T) were found high $(\geq 40)$ both preoperatively and 6 months postoperatively. Postoperatively there was no significant decrease of the levels of anxiety.

The patients' repeated analysis of SF-36 and STAI Scores at baseline and 6-month follow-up are summarized in Table III.

\section{Discussion}

Health-related quality of life is one of the primary goals of treatment in patients with peripheral arterial disease; however, HRQoL is rarely measured directly. Recently HRQoL has been increasingly considered an important patient-oriented outcome measurement of cardiovascular interventions [17-19].

The advances in perioperative anesthesia and intensive care have provided a significant decrease in mortality in perioperative or postoperative course. Considering that mortality has become relatively low after vascular surgery, development in health condition, modifications in functioning condition and feeling of well-being have come to be important indicators of the end result of peripheral vascular surgery $[2,4]$. Recovery from peripheral arterial disease is not totally determined by means of physical attributes and medical remedies but social and mental factors can also influence the long-term healing [3, 19]. Despite good results of operations, morbidity-free and mortality-free courses, those parameters alone do not give sufficient data on a patient's functional, emotional, and mental well-being [20]. Health-related quality of life can affect postoperative life for several reasons: complications of surgical therapy, recurrence or occurrence of non-vascular diseases, neurological and psychological complications, etc. Therefore, postoperative high quality of existence after these operations has become a crucial measure of the effectiveness of the vascular surgical procedure [21].

Health-related quality of life (HRQoL) contains an individual's physical, emotional, and psychologic health, social and functional condition. However, a reliable, valid, responsive, sensitive standardized method that covers all health domains is necessary [22].

Questionnaires are the most often used technique of measuring quality of life. The 36-item Medical Outcomes Short-Form Health Survey self-administered questionnaire (SF-36) (Medical Outcomes Trust, Boston, MA) is a multipurpose, short-form health survey with only 36 questions [15]. The SF-36 Health Survey is one of the most useful standardized questionnaires provided to examine the functional status and well-being of patients and related to activities of daily life [13].

The Spielberger State-Trait Anxiety Inventory is one of the first tests that evaluates state and trait anxiety symptoms at the same time. The StateTrait Anxiety Inventory (STAI) consists of two 20item scales that measure "state" (current) and "trait" anxiety (general) (STAI-S / STAI-T) [16]. The STA/ tests diagnose the level of anxiety and distinguishes it from depressive syndromes [23].

Table III. Repeated-measures analysis of SF-36 score at baseline $(n=335)$ and 6-month follow-up $(n=304)$

\begin{tabular}{|c|c|c|c|}
\hline SF-36 & Baseline & 6-month follow-up & $P$-value \\
\hline Physical functioning & $51.7(21.1)$ & $57.6(25.4)$ & 0.08 \\
\hline Role limitation, physical health & $23.5(34.6)$ & $30.6(44.9)$ & 0.06 \\
\hline Bodily pain & $53.2(24.2)$ & $56.8(26.5)$ & 0.07 \\
\hline Social functioning & $52.6(18.4)$ & $60.4(21.1)$ & 0.03 \\
\hline General health & $44.4(19.2)$ & $51.4(16.4)$ & 0.08 \\
\hline Role limitation, emotional & $66.5(25.4)$ & $70.6(23.2)$ & 0.2 \\
\hline Vitality, energy, or fatigue & $56.8(46.5)$ & $68.4(40.2)$ & 0.07 \\
\hline General health perception & $60.5(27.6)$ & $75.1(21.1)$ & 0.04 \\
\hline Physical component & $35.6(13.3)$ & $37.5(13.2)$ & 0.2 \\
\hline Mental component & $39.2(23.6)$ & $43.0(24.5)$ & 0.4 \\
\hline \multicolumn{4}{|l|}{ STAI: } \\
\hline STAI-S & $47 \pm 10.1$ & $44 \pm 8.5$ & NS \\
\hline STAI-T & $45 \pm 9.2$ & $44 \pm 6.5$ & NS \\
\hline
\end{tabular}

SF-36 - Short-Form Health Survey, STAI - State-Trait Anxiety Inventory, STAI-S - State-Trait Anxiety Inventory "state" (current), STAI-T - State-Trait Anxiety Inventory "trait" (chronic). 
The most commonly used questionnaires in cardiovascular diseases are the World Health Organization Quality Of Life Assessment Instrument (WHOQOL) (7), the Nottingham Health Profile (NHP) [24], the Euro-Quality of Life Questionnaire (EuroQoL, EQ-5D) [25], and the Medical Outcomes Study 36-item Short-Form Health Survey (SF-36) [15].

The World Health Organization Quality of Life Questionnaire (WHOQOL) was developed by a multicenter international study and includes six factors: physical condition, independence statement, mental health, social relations, spirituality/ religiousness/personal beliefs, and environment [26]. A shorter version of the questionnaire was provided (WHOQOL-Bref) [27, 28].

The Nottingham Health Profile (NHP) includes two parts. The domains addressed include the bodily, intellectual, and emotional spheres, as well as the respondent's social relationships. The score does not ignore the respondents' accurate well-being, but mostly analyzes the poor elements in their functioning [24].

The Euro-Quality of Life Questionnaire (EuroQoL, EQ-5D) offers a questionnaire with extraordinary sensitivity to short-term changes, but the fluctuations of the effects are important, impeding use of this tool [25].

The other most commonly used questionnaires in cardiovascular diseases are the Minnesota Living with Heart Failure (MLHF) questionnaire [29] and the MacNew Heart Disease Health-Related Quality of Life Questionnaire (MacNew) [30]. The Minnesota Living with Heart Failure Questionnaire is used in the evaluation of chronic heart failure patients [29]. The MacNew Heart Disease Health-Related Quality of Life Questionnaire (MacNew) was developed as an alteration of the Quality of Life after Myocardial Infarction Questionnaire (QLMI) [30]. Its purpose is to evaluate patients after myocardial infarction or with coronary artery disease or heart failure [30].

A well-recognized $\mathrm{HRQOL}$ instrument is the Medical Outcomes Survey Short-Form 36 (SF-36) [31]. Studies have demonstrated that one of the most appropriate methods to assess cardiovascular diseases HRQoL is the SF-36 survey [18, 32-35]. The SF-36 questionnaire was developed during the Medical Outcomes Study to evaluate the general health condition of various patient groups [15]. It is a self-administered instrument that takes about 15 minutes to complete. A Turkish version is available [13].

Anxiety was described by Freud as "something felt", an emotional state that blanketed feelings of apprehension, tension, anxiety, and fear followed with the aid of physiological arousal. Anxiety before a surgical procedure was accepted as a vital aspect for postoperative complications. It has been also discovered that patients with a high degree of preoperative anxiety respond worse to analgesic medication than patients with a low stage of lower anxiety [36]. Among coronary heart disease patients undergoing coronary artery bypass grafting, anxiety was detected commonly and showed an association with an increased all-cause mortality risk. Although anxiety and depression was undoubtedly and particularly correlated in those patients, only anxiety was found associated with improved mortality and morbidity.

Improved quality of life has come to be one of the most critical effects of lower extremity peripheral arterial disease [37-40]. The research has cautioned that the experience and recovery process after a cardiovascular operation may be more complicated than anticipated [41]. Particularly anxiety and depression seem to affect the postoperative process and specific quality of life after vascular intervention and/or surgery [42] The reviews on the benefits of vascular surgical treatment have centered on postoperative subjective health outcomes in terms of functional status, activity level, daily life activity, return to work, psychological well-being and self-reported health-related functional status as well as objective negative cardiac events, survival and complication rates [2, 20, 42].

Despite there not having been any significant morbidity and success of vascular intervention with high graft patency, significant improvement in only two out of eight health domains - social functioning $(p<0.03)$ and general health perception $(p<0.04)$ - was found at 6-month follow-up in our series. The findings of the present study imply that most of the patients with lower preoperative HRQoL included in the study were classified as presenting clinically significant anxiety symptoms and there was no significant decrease of the levels of trait and state anxiety postoperatively. Also the education level of the series was considerably low, with a mean of 6.95 years; the majority of patients have had education to secondary school level. This findings led to the conclusion that a preoperative high level of trait anxiety continued postoperatively and affected the perception of quality of life postoperatively. The results of the present study suggest that the assessment of psychosocial factors, particularly the ongoing assessment of anxiety using trait (chronic) and state (current) STA levels, could help in risk stratification of patients' functional status of HRQoL but also postoperative results prediction.

Poor HRQoL and anxiety should be recognized and thoroughly considered within other positive awareness procedures [43]. The selected interventions about anxiety of patients preoperatively may have inspired the well-being after vascular 
surgery. Measurement of HRQoL should be considered as a routine evaluation to gain a whole picture of the patients' situation and strengthen conclusions about the effectiveness of therapy.

There is a growing recognition of the importance of psychosocial factors in the recovery from cardiovascular surgical procedures [18]. Important predictors of advanced high-quality lifestyles consequences contain age, gender education, and comorbidities [17]. Preoperative mood and cognitive performances are also relevant predictors for early postoperative psychological dysfunctions, which might be related to extended hospitalization and mortality after a surgical operation [2].

Clinicians, patients, and relatives should be aware about this probability, and an attempt should be made at the preoperative identification of patients predisposed to severe chronic stress [37, 40, 43]. Moreover, cardiovascular surgeons need to be aware of their patients' psychosocial functioning and, if necessary, advise them to take expert guidance and help to maximize well-being. Furthermore, the assessment of preoperative well-being should be integrated in routine care in order to identify and support patients with higher levels of anxiety for a full understanding of how peripheral vascular disease affects patients individually.

One of the limitations is that the demographic variables may have had significant interactions with the variables anxiety and HRQoL but were not included in the regression analysis. Another limitation is that the SF-36 asks patients about typical daily activities. Future studies are warranted to evaluate demographic variables and physical health status as predictors of benefits from cardiovascular surgery.

In conclusion, a patient's operative risk as well as SF-36 and STAI scores should be assessed. Multicenter and larger studies are warranted to assess effects of different psychosocial factors on long-term mortality and morbidity.

\section{Conflict of interest}

The authors declare no conflict of interest.

\section{References}

1. Beyaz MO, Ugurlucan M, Oztas DM, et al. Evaluation of the relationship between plaque formation leading to symptomatic carotid artery stenosis and cytomegalovirus by investigating the virus DNA. Arch Med Sci Atheroscler Dis 2019; 4: e19-24.

2. Ghosh SK, Majumder M. Quality of life as a predictor of postoperative outcome following revascularization of peripheral arterial disease. Int Surg J 2018; 5: 315-9.

3. Kolh P. Improving quality of life in patients with peripheral arterial disease: an important goal. Eur J Vasc Endovasc Surg 2010; 40: 626-7.

4. Regensteiner JG, Hiatt WR, Coll JR, et al. The impact of peripheral arterial disease on health-related quality of life in the Peripheral Arterial disease awareness, Risk, and Treatment: New Resources for Survival (PARTNERS) Program. Vasc Med 2008; 13: 15-24.

5. Long J, Modrall JG, Parker BJ, Swann A, Welborn MB, Anthony T. Correlation between ankle-brachial index, symptoms, and health-related quality of life in patients with peripheral vascular disease. J Vasc Surg 2004; 39: 723-7.

6. WHOQOL Group. Study Protocol for the World Health Organisation project to develop a quality of life assessment instrument (WHOQOL). Qual Life Res 1993; 2: 153-9.

7. The WHOQOL Group. The Development of the World Health Organization Quality of Life Assessment Instrument (the WHOQOL). In:Orley J, Kuyken W. (eds) Quality of Life Assessment: International Perspectives. Springer, Berlin, Heidelberg 1994.

8. The World Health Organization Quality of Life assessment (WHOQOL): position paper from the World Health Organization. Soc Sci Med 1995; 41: 1403-9.

9. Szabo S. The World Health Organization Quality of Life (WHOQOL) assessment instrument. In: Quality of life and pharmacoeconomics in clinical trials. Spilker B (ed.). Lippincott-Raven Publishers, Philadelphia 1996; 355-62.

10. World Health Organization, Division of Mental Health and Prevention of Substance Abuse. 1997, WHOQOL measuring Quality of life. Geneva, Switzerland: World Health Organization.

11. Wiebe S, Guyatt G, Weaver B, Matijevic S, Sidwell C. Comparative responsiveness of generic and specific quality-of life instruments. J Clin Epidemiol 2003; 56: 52-60.

12. Guyatt GH, Ferrans CE, Halyard MY, et al. Exploration of the value of health-related quality-of-life information from clinical research and into clinical practice. Mayo Clin Proc 2007; 82: 1229-39.

13. Aydemir Ö. Konsültasyon-Liyezon psikiyatrisinde yaşam kalitesi ölçümü: Kısa Form-36 (SF-36). Psikiyatri Psikoloji Psikofarmakoloji Dergisi 1999.

14. Spielberger C. Manual for the State-Trait Anxiety Inventory (rev. ed.). Palo Alto (CA): Consulting Psychologists Press 1983.

15. Ware JE, Kosinski M, Dewey JE. Changes between version 1 and version 2. In: How to score version 2 of the SF-36 Health Survey (Standard and Acute forms). Ware JE, Kosinski M, Dewey JE (eds.). Quality Metric Incorporation, Lincoln 2002.

16. Spielberger CD, Sydeman SJ, Owen AE, Marsh BJ. Measuring anxiety and anger with the State-Trait Anxiety Inventory (STAI) and the State-Trait Anger Expression Inventory (STAXI). In: The use of psychological testing for treatment planning and outcomes assessment. Maruish ME (ed.). Mahwah NJ, Lawrence Erlbaum Associates Publishers, 1999; 993-1021.

17. Güzelhan Y, Conkbayır C, Uğurlucan M, Yıldız CE, Alpagut $U$, Bozbuğa N. Gender differences in patients with anxiety after coronary artery bypass surgery. Heart Surg Forum 2018; 21: e165-9.

18. Güzelhan Y, Uğurlucan M, Öztaş DM, et al. Anxiety and health-related quality of life after cardiac surgery. Arch Medical Sci Atheroscler Dis 2020; 5: 27-35.

19. Graf J, Koch M, Dujardin R, Kersten A, Janssens U. Health-related quality of life before, 1 month after, and 9 months after intensive care in medical cardiovascular and pulmonary patients. Crit Care Med 2003; 31: 2163-9.

20. Feinglass J, Morasch M, McCarthy WJ. Measures of success and health-related quality of life in lower-extremity vascular surgery. Ann Rev Med 2000; 51: 101-13. 
21. Dziedzic EA, Gąsior JS, Pawłowski M, et al. Vitamin D level is associated with severity of coronary artery atherosclerosis and incidence of acute coronary syndromes in non-diabetic cardiac patients. Arch Med Sci 2019; 15: 359-68.

22. Khanna D, Tsevat J. Health-related quality of life an introduction. Am J Manag Care 2007; 13: 218-23.

23. Grös DF, Antony MM, Simms LJ, McCabe RE. Psychometric properties of the State-Trait Inventory for Cognitive and Somatic Anxiety (STICSA): comparison to the StateTrait Anxiety Inventory (STAI). Psychol Assess 2007; 19: 369-81.

24. Lukkarinen $\mathrm{H}$, Hentinen $\mathrm{M}$. Assessment of quality of life with the Nottingham Health Profile among patients with coronary heart disease. J Adv Nurs 1997; 26: 73-84.

25. EuroQol - a new facility for the measurement of health-related quality of life. The EuroQol Group. Health Policy 1990; 16: 199-208.

26. WHOQOL: Measuring Quality of Life. https://www.who. int/healthinfo/survey/whoqol-qualityoflife/en/index1. html

27. WHO Quality of Life-BREF (WHOQOL-BREF). https:// www.who.int/substance_abuse/research_tools/whoqolbref/en/

28. WHOQOL-BREF Introduction, administration, scoring and generic version of the asssessment. https://www. who.int/mental_health /media/en/76.pdf

29. Riegel B, Moser DK, Glaser D, et al. The Minnesota Living With Heart Failure Questionnaire: sensitivity to differences and responsiveness to intervention intensity in a clinical population. Nurs Res 2002; 51: 209-18.

30. Dixon T, Lim L, Oldridge NB. The MacNew health-related quality of life instrument: reference data for users. Qual Life Research 2002; 11: 173-83.

31. Ware JE, Sherbourne CD. The MOS 36-item short form health survey (SF-36): I. Conceptual framework and item selection. Med Care 1992; 30: 473-83.

32. Supino PG, Borer JS, Franciosa JA, et al. Acceptability and psychometric properties of the Minnesota Living With Heart Failure Questionnaire among patients undergoing heart valve surgery: validation and comparison with SF-36. J Card Fail 2009; 15: 267-77.

33. Prieto L, Alonso J, Ferrer M, Anto JM. Are results of the SF-36 health survey and the Nottingham Health Profile similar? A comparison in COPD patients. Quality of Life in COPD Study Group. J Clin Epidemiol 1997; 50: 463-73.

34. Kiebzak GM, Pierson LM, Campbell M, Cook JW. Use of the SF-36 general health status survey to document health-related quality of life in patients with coronary artery disease: effect of disease and response to coronary artery bypass graft surgery. Heart Lung 2002; 31: 207-13.

35. Failde I, Ramos I. Validity and reliability of the SF-36 Health Survey Questionnaire in patients with coronary artery disease. J Clin Epidemiol 2000; 53: 359-65.

36. Greszta E, Siemińska MJ. Relationship of preoperative anxiety-state and anxiety-trait in patients qualified for coronary artery bypass graft surgery to the perception of postoperative pain and other pain complaints. Ann Acad Med Stetin 2008; 54: 157-63.

37. Sasajima T, Sasajima Y, Akazawa K, Saito Y. Arterial reconstruction for patients with chronic limb ischemia improves ambulatoryfunction and health-related quality of life. Ann Vasc Surg 2020; 66: 518-28.

38. Wilson WRW, Fitridge RA, Weekes AJ, Morgan C, Tavella R, Beltrame JF. Quality of life of patients with periph- eral arterial disease andchronic stable angina. Angiology 2012; 63: 223-8.

39. Monaro S, West S, Gullick J. An integrative review of health-related quality of life in patients with critical limb ischaemia. J Clin Nurs 2017; 28: 2826-44.

40. Hallin A, Bergqvist D, Fugl-Meyer K, Holmberg L. Areas of concern, quality of life and life satisfaction in patients with peripheral vascular disease. Eur J Vasc Endovascr Surg 2002; 24: 255-63.

41. Uğurlucan M, Önal Y, Öztaş DM, Odabaş AR, Alpagut U. Transplanted kidney, stenotic renal artery, and a giant pseudoaneurysm: how we tried to treat, why we failed, and how we managed? Turk Gogus Kalp Damar Cerrahisi Derg 2019; 27: 114-7.

42. Remes L, Isoaho R, Vahlberg T, Viitanen M, Rautava P. Quality of life among lower extremity peripheral arterial disease patients who have undergone endovascular or surgical revascularization: a case-control study. Eur J Vasc Endovasc Surg 2010; 40: 618-25.

43. Breek JC, De VJ, van Heck GL, Van Berge Henegouwen DP, Hamming JF. Assessment of disease impact in patients with intermittent claudication: discrepancy between health status and quality of life. J Vasc Surg 2005; 41: 443-50. 